\title{
IMPLEMENTASI PEMBELAJARAN SAINS KIMIA BERBASIS EKSPERIMEN MENGGUNAKAN APLIKASI VIRTUAL LAB AUTHORING TOOL CHEMCOLLECTIVE
}

\author{
Abu Bakar ${ }^{1 *}$ Haryanto $^{2}$, Afrida $^{3}$, Aulia Sanova ${ }^{4}$ \\ ${ }^{1,2,3,4}$ Fakultas Keguruan dan Ilmu Pendidikan, Universitas Jambi \\ "Corresponding Author Email : bakarabu@ unja.ac.id
}

(Artikel Masuk: 15 Desember 2020; Artikel Diterima: 24 Desember 2020; Artikel Terbit: 26 Desember 2020)

\begin{abstract}
Virtual laboratories play an important role as a medium that can be used to support and anticipate limitations in real laboratories. This activity aims to provide teachers with practical skills knowledge in learning chemistry lab work by applying a computer-assisted virtual program with the Chemcollective Authoring Tool as an alternative effort to overcome the limitations of real laboratories in schools. The participants were science teachers at SMPIT Uswatun Hasanah Jambi City. The methods used in this training are demonstration, practice and mentoring. The results of the activities achieved through this activity were increased knowledge and competence of teachers on the implementation of ICT-based chemistry practicum methods. The teacher seems to be very skilled at practicing the simulations offered and even the teacher also has a great curiosity to try other virtual science lab simulations. This training is very useful because it can help teachers overcome obstacles in learning science concepts that require practicum with limited availability of tools and materials.
\end{abstract}

Keywords: Chemcollective Authoring Tool, Chemistry Experiment, Laboratory virtual.

\begin{abstract}
Abstrak
Laboratorium virtual berperan penting sebagai media yang dapat digunakan dalam menunjang dan mengantisipasi keterbatasan pada laboratorium nyata. kegiatan pengabdian ini bertujuan memberi pengetahuan practical skill guru dalam pembelajaran praktikum IPA kimia dengan mengaplikasikan program virtual berbantuan komputer Authoring Tool Chemcollective sebagai upaya alternatif menanggulangi keterbatasan laboratorium ril di sekolah. Peserta pelatihan adalah guru sains IPA di SMPIT Uswatun Hasanah Kota Jambi. Metode yang digunakan dalam pelatihan ini berupa demonstrasi, praktek dan pendampingan. Hasil kegiatan yang dicapai melalui kegiatan ini adalah bertambahnya pengetahuan dan kompetensi guru tentang pelaksanaan metode praktikum kimia berbasis TIK. Guru terlihat sudah sangat terampil mempraktekkan simulasi yang ditawarkan bahkan guru juga memiliki rasa ingin tau yang besar untuk mencoba simulasi virtual lab sains lainnya. Pelatihan ini dirasa sangat bermanfaat sekali karena dapat membantu guru mengatasi hambatan dalam mempelajari konsep-konsep IPA yang membutuhkan praktikum dengan ketersediaan alat dan bahan yang terbatas.
\end{abstract}

Kata Kunci: Authoring Tool Chemcollective, Eksperimen, Kimia, Laboratorium Virtual 


\section{A. PENDAHULUAN}

Dalam proses pembelajaran guru berperan sebagai salah satu faktor penting dan memiliki tanggung jawab penuh serta diharapkan dapat menciptakan suasana belajar yang melibatkan siswa aktif. Oleh karenanya, guru dituntut untuk dapat memanfaatkan serta mau belajar, mengerti, memahami dan mampu menggunakan teknologi sebagai media pembelajaran sehingga dapat meningkatkan mutu pendidikan. Hal ini juga diamanatkan dalam Undang-Undang nomor 14/2005 tentang guru dan dosen yang menyatakan bahwa setiap pendidik harus dapat memanfaatkan teknologi informasi dan komunikasi untuk kepentingan penyelenggaraan kegiatan pengembangan yang mendidik.

Sains atau Ilmu Pengetahuan IPA merupakan ilmu yang berkaitan dengan cara mencari tahu tentang alam secara sistematis yang meliputi empat unsur utama yaitu sikap, proses, produk dan aplikasinya dengan mensinergikan beberapa keterampilan sains seperti kemampuan mengamati, mengidentifikasi, memprediksi, mengukur, menganalisis dan mengolah data serta menyimpulkan. Dalam hal ini siswa di tuntut belajar aktif serta mengembangkan kemampuan berpikir sains layaknya seorang ilmuwan dan sikap kritis siswa.

Ilmu kimia merupakan salah satu bagian atau rumpun yang terintegrasi pada mata pelajaran sains atau IPA. Keberadaan ilmu kimia di Indonesia mulai di ajarkan pada jenjang SMP/MTs. Hal ini berbeda dengan negara Inggris, Filipina, Singapura dan Australia yang telah mengenalkan bahan kajian kimia sejak tingkat SD. Adapun upaya ini diharapkan agar guru berusaha mempersiapkan diri sebaik-baiknya dan bagi siswa, diharapkan dengan belajar kimia dapat diterima dengan baik, lebih termotivasi dan memiliki rasa ketertarikan dalam belajar. Kurikulum materi ilmu kimia di SMP/MTs pun dikemas dengan konsep yang sederhana, aplikatif dan sangat dekat dalam kehidupan sehari-hari, sehingga tidak diasumsikan di awal jika kimia adalah pelajaran yang sulit. Namun faktanya Di beberapa Negara, banyak siswa cenderung mendeskripsikan jika pelajaran kimia adalah pelajaran yang sulit dan membosankan karena memuat konsepkonsep abstrak sehingga siswa tidak mampu mengaitkan antara teori yang diketahui dengan penerapannya (Orgill \& Bodner, 2004).

Pada dasarnya ilmu kimia sendiri adalah ilmu yang mempelajari tentang sifat, struktur dan komposisi, susunan suatu zat serta energi yang menyertai perubahan suatu zat itu sendiri dan tidak hanya membahas objek suatu materi yang bersifat teoritis yang berupa fakta, teori, konsep, prinsip dan hukum saja tetapi juga mencoba untuk membahas tentang sesuatu yang sifatnya 
empiris yang dapat diperoleh dengan produk kerja ilmiah dengan melakukan praktikum. Belajar akan bermakna jika siswa mampu mengaitkan konsep yang bersifat logika abstrak dengan pengalaman nyata baik dalam kehidupan sehari-hari maupun dalam skala laboratorium. Pemilihan metode praktikum harus disesuaikan dengan karakteristik materi dari kimia itu sendiri.

Namun tidak semua sekolah dapat melakukan kegiatan praktikum dikarenakan berbagai kendala seperti mahalnya harga alat dan bahan praktikum sehingga tidak terjangkau untuk sekolah-sekolah yang kurang mampu, terbatasnya waktu untuk persiapan dan dan pelaksanan praktikum, jumlah alat dan bahan yang tidak sesuai dengan banyaknya siswa dan resiko keamanan saat praktikum menjadi kendala dalam pelaksanaan praktikum (Tuysuz, 2010). Namun faktanya laboratorium tidak hanya harus memberikan kesempatan untuk meningkatkan kemampuan analisis mereka, tetapi juga untuk memberikan keterlibatan siswa aktif sambil belajar (Woodfield, 2004).

Seiring dengan perkembangan informasi dan komunikasi yang berbasis komputer, maka eksperimen kimia di kelas dapat dilakukan dengan menggunakan laboratorium virtual (Hamida et al, 2013). Karakteristik laboratorium virtual ini adalah program yang berisi alat-alat laboratorium yang berfungsi sebagaimana alat riil sehingga membantu siswa mengamati langkah-langkah percobaan sambil memperhatikan gambar, seolah-olah mereka melakukan interaksi melakukan eksperimen mandiri yang dapat dilakukan dimanapun dan kapanpun (Sanova, 2017). Salah satu software simulasi virtual lab yang berhasil dikembangkan oleh Carneige Mellon University adalah Chemcollective. Berbagai situs resmi telah menyediakan alat bantu tersebut yang dapat diunduh secara gratis pada situs http://www.chemcollective.org/ terutama pada mata pelajaran sains (kimia, biologi, fisika dan matematika). Virtual lab Chemcollective dapat memberikan pengalaman belajar yang lebih konkret melalui penciptaan tiruan-tiruan bentuk pengalaman mendekati suasana sebenarnya dan berlangsung dalam suasana tanpa resiko.

Guru sangat menyadari sekali akan pentingnya praktikum untuk pemahaman konsep, namun di beberapa sekolah SMP/MTs di Kota Jambi, praktikum sains kimia itu sendiri jarang dilakukan dikarenakan keterbatasan alat dan bahan yang tidak memadai sehingga guru hanya melakukan pembelajaran secara langsung dengan menjelaskan konsep materi, latihan dan penugasan tanpa ada pengujian yang kuat yaitu berupa praktikum di laboratorium. 
Disamping itu dalam melaksanakan praktikum membutuhkan waktu yang cukup lama dalam mempersiapkan alat dan bahan sementara alokasi waktu pembelajaran sangat terbatas. Untuk itu perlunya tambahan media pembelajaran yang menambah pemahaman materi pelajaran yang memerlukan praktikum.

Berdasarkan kondisi nyata dari permasalahan diatas, tim civitas akademika FKIP UNJA mencoba membantu dan memberi alternatif guna mengatasi keterbatasan laboratorium IPA dengan melakukan pendampingan bagi guru-guru IPA dengan membekali pengetahuan dan keterampilan dalam menggunakan dan mengelola lab dalam bentuk virtual dan dapat mengimplementasi proses pembelajaran khususnya dalam pelaksanaan praktikum kimia menggunakan software Chemcollective, sehingga bagi siswa pembelajaran menjadi lebih menarik dan guru dapat mengantisipasi keterbatasan waktu, alat dan bahan praktikum sesuai dengan kebutuhan siswa dan kondisi sekolah. Adapun Target dalam kegiatan pengabdian ini adalah membantu meningkatkan keterampilan kompetensi practical skill guru sehingga mampu mengoperasikan aplikasi software Chemcollective sebagai media penunjang kegiatan praktikum virtual di kelas.

\section{B. PELAKSANAAN DAN METODE}

Sasaran yang dituju dalam kegiatan pengabdian ini adalah guru dan siswa IPA SMPIT Uswatun Hasanah Kota Jambi. Pemilihan sekolah atas pertimbangan ketersediaan sarana labor, alat dan bahan disekolah mengingat sekolah ini baru berdiri.

Kegiatan Pelatihan pelatihan ini dilaksanakan dengan menggunakan beberapa cara, yaitu dengan metode ceramah, diskusiinformasi/Tanya jawab, demonstrasi dan percobaan langsung. Secara rinci metode yang digunakan dapat diuraikan sebagai berikut :

1. Melakukan persepsi awal guna memotivasi siswa dalam belajar

2. Menjelaskan konsep materi

3. Implementasi praktek dan menginvestigasi masalah selama melakukan kegiatan praktikum secara virtual.

4. Meminta respon atau tanggapn guru terhadap penggunaan media lab virtual

Pada saat kegiatan berlangsung, evaluasi dilakukan secara lisan dan spontan berupa tanya jawab. Materi yang belum jelasakan diulang kembali serta kesalahankesalahan dalam proses pelaksanaan praktikum. Proses pelaksanaan praktikum dilengkapi dengan perangkat ajar berupa LKPD dan petunjuk praktikum, sehingga memudakan guru dan siswa nantinya dalam memahami konsep. 


\section{HASIL DAN PEMBAHASAN}

Teknologi yang diperlukan dalam kegiatan pengabdian ini adalah Laptop atau komputer dan LCD yang akan digunkaan dalam proses penyampaian materi dan kamera untuk dokumentasi kegiatan. Kegiatan pengabdian dilakukan selama satu hari yang dilaksanakan pada hari Selasa tanggal 28 Juli 2020. Sebelum kegiatan inti pelatihan dimulai, tim dosen selaku pelaksana dibantu oleh dua orang mahasiswa terlebih dahulu memberikan pelatihan bagaimana cara melakukan penginstalan program

Chemcollective.

Metode yang digunakan dalam kegiatan pengabdian ini berupa pelatihan dan pendampingan implementasi penggunaan media pembelajaran berbasis laboratorium virtual bagi guru IPA SMPIT Uswatun Hasanah Kota Jambi melalui beberapa tahap kegiatan mulai dari persiapan awal, pelaksanaan dan evaluasi.

1. Tahap persiapan. Pada tahap persiapan, tim abdimas melakukan survei pendahuluan untuk menganalisis lokasi mitra, kebutuhan pelatihan yang dibutuhkan mitra, dan menyusun rancangan kegiatan yang akan dilakukan, serta menyusun instrumen dan modul penuntun serta LKPD

2. Tahap pelaksanaan. Pada tahap ini, tim abdimas, melakukan pelatihan simulasi penggunaan media Chemcollective yang ditujukan kepada guru IPA dengan tujuan agar guru dapat meningkatkan kompetensi dan kemahiran menggunakan simulasi virtual ini. Selain itu, kegiatan ini diharapkan dapat dijadikan bahan rujukan bagi guru untuk menerapkan simulasi praktikum yang disebabkan pengetahuan guru berkenaan dengan penggunaan virlab yang masih minim serta belum tersedianya stok bahan-bahan kimia karena harganya yang lumayan mahal

3. Tahap evaluasi. Pada tahap ini, tim abdimas melakukan evaluasi terhadap proses kegiatan. Evaluasi dilakukan dimulai dari sebelum pelaksanaan sampai akhir yang meliputi antusiasme dan respon peserta, kemampuan merecall serta keterampilan guru dalam menggunakan simulasi.

Selama proses pelaksanaan kegiatan, tim dosen pengabdian juga dibantu oleh beberapa mahasiswa yang berperan membantu melakukan penginstalan program laboratorium virtual Chemcollective pada laptop guru. Sebelum menuju kegiatan inti yaitu praktek simulasi maka di berikan dulu pemaparan materi tentang pengantar seputar lab vitual Chemcollective dan pengenalan komponen-komponen yang terdapat pada laboratorium virtual. Guru juga diberikan beberapa contoh pemodelan cara mengaplikasikan media laboratorium virtual dalam pembelajaran. 


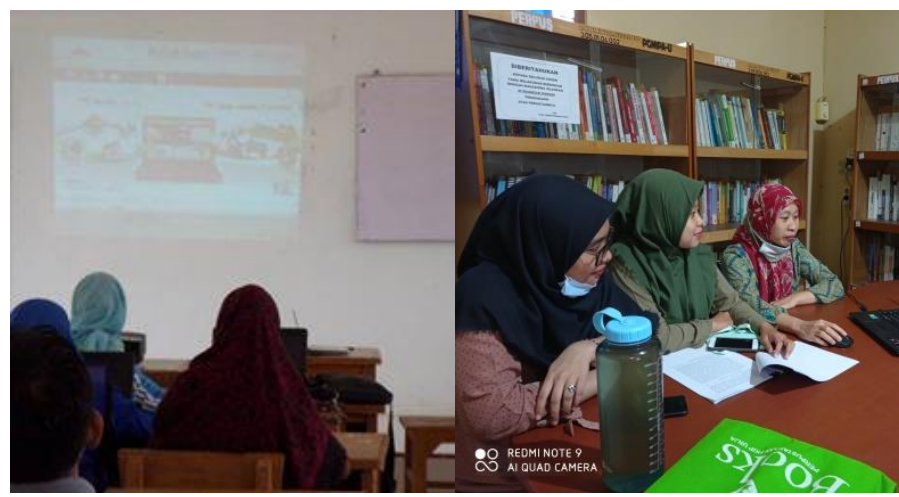

\section{Gambar 1a.}

Penyampaian materi
Gambar 1 b.

Briefing Penggunaan Virlab Bersama Mahasiswa

Pada kegiatan pengabdian ini materi pelajaran kimia yang disajikan sebagai bahan

pelatihan adalah materi asam basa dalam memahami sifat kosentnrasi larutan asambasa. Pemilihan ini dipertimbangkan karena konten materinya yang ringan dan masih relevan jika diajarkan untuk siswa SMP. Agar memudahkan guru dalam penggunaan simulasi praktikum maka tim pengabdi juga memberikan petunjuk penggunaan dan juga Lembar Kerja Peserta Didik sebagai bahan ajar latihan dan evaluasi agar tercapai kompetensi siswa dalam belajar.

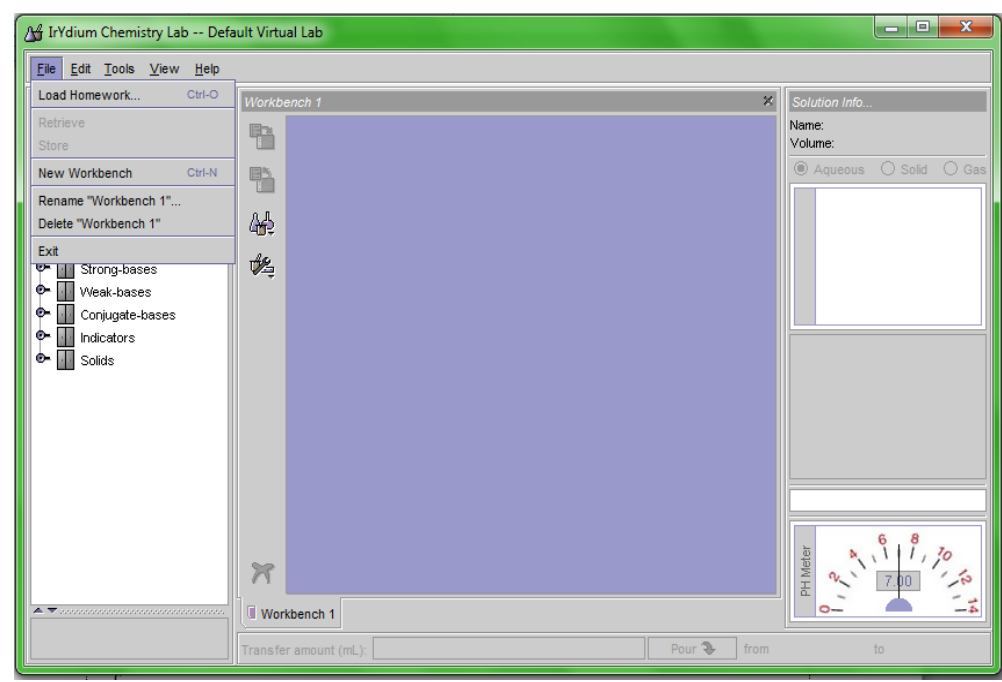

Gambar 2. Tampilan Meja Kerja Lab Vitual Chemcollective

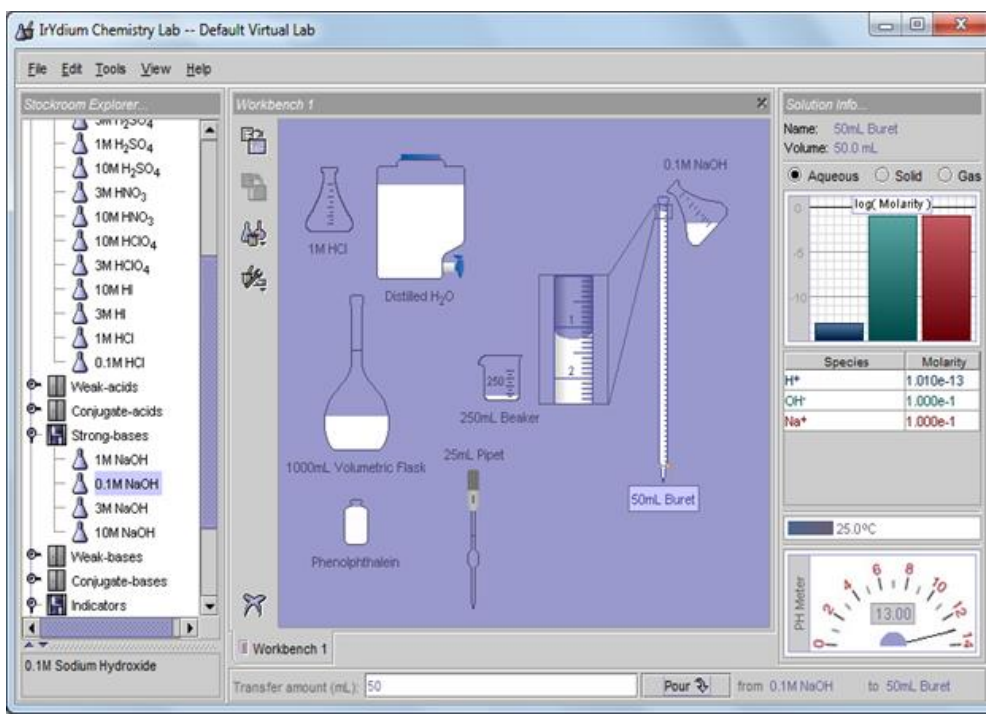

Gambar 3. Alat dan Bahan serta Simulasi Kerja Percobaan Titrasi 
Kegiatan praktikum materi asam-basa menggunakan lab vitual chemcollective ini bertujuan memberi pengetahuan dan pemahaman bagi guru tentang cara kerja dan pengoperasian teknik melakukan percobaan melakukan pengenceran, pembuatan larutan dan menghitung kosentrasi dalam percobaan titrasi menggukan alat dan bahan yang dikemas berbentuk virtual namun didesain selayaknya objek sungguhan.

Sebagai bahan evaluasi kompetensi bagi guru, maka dalam proses pelatihan guru diberi kesempatan untuk berlatih dan merecall kembali pengetahuan yang telah didapat dengan presentasi diskusi dan praktek. Secara keseluruhan rata-rata kemampuan guru mengoperasikan simulasi sebesar 92\% dengan kategori sangat terampil, guru juga menyatakan $90 \%$ meyakini penyajian materi yang dihadirkan secara konkrit dalam bentuk praktikum dan permainan diyakini dapat memotivasi dan menarik siswa dalam belajar, sehingga juga akan berdampak pada hasil belajar dan $93 \%$ guru juga menyatakan jika petunjuk yang disajikan sangat mudah dipahami sehingga mudah untuk dipraktekkan. Dapat disimpulkan 90\% respon guru sangat positif. Guru menyatakan bahwa dengan mengikuti pelatihan ini pengetahuan dan pengalaman guru baik secara empiris maupun praktis menjadi bertambah. Pelatihan ini juga dirasa sangat bermafaat karena dapat membantu guru mengatasi hambatan dalam mempelajari konsep-konsep IPA yang membutuhkan praktikum dengan ketersediaan alat dan bahan yang terbatas. Guru juga menjelaskaan kehadiran simulasi ini dirasa sangat baik bagi siswa juga, karena dapat dijadikan sebagai kemampuan awal dalam mengkonstruk pengetahuan mereka dalam mempelajari materi kimia selanjutnya di jenjang SMA dan para peserta menyadari bahwa di era teknologi informasi saat ini praktik IPA dapat diaplikasikan dengan mudah dengan memanfaatkan fitur maya sehingga menambah pengetahuan dan wawasan guru sebagai sumber referensi mengajar yang membutuhkan keterampilan hard skill.

\section{PENUTUP}

\section{Simpulan}

Secara umum kegiatan pengabdian ini berjalan lancar dan hasil capaian yang diperoleh melalui kegiatan ini adalah bertambahnya pengetahuan dan kompetensi guru tentang pelaksanaan metode praktikum IPA kimia berbasis TIK menggunakan simulasi aplikasi lab vitual chemcollective sehingga praktikum tetap dilaksanakan meskipun dijalankan secara virtual guna mengatasi pelaksanaan praktikum yang tidak dilakukan secara riil. 


\section{Saran}

Kegiatan pengabdian ini dirasa bermanfaat oleh peserta sebagai sarana pengenalan dan pembelajaran yang baru mengenai penggunaan media simulasi praktikum berbasis TIK dengan simulasi chemcollective. Oleh karena itu perlu dilakukan pengabdian serupa dikalangan MGMP guru-guru bidang studi IPA kimia SMP di sekolah-sekolah lainnya.

\section{E. UCAPAN TERIMAKASIH}

Pada kesemptan ini, Kami menyampaikan ucapan terimakasih yang tiada terhingga kepada :

1. Ketua Ketua Lembaga Pengabdian Kepada Masyarakat Universitas Jambi yang telah mendanai kegiatan ini. Tanpa bantuan sumber dana ini sangat sulit bagi kami untuk dapat menyelenggarakan kegiatan pengabdian.

2. Kepala SMPIT Uswatun Hasanah Kota Jambi yang telah memberi izin atas tempat dan waktunya sehingga kegiatan ini dapat berjalan lancar serta guru bidang studi IPA yang telah ikut berpartisipasi dalam pelaksanaan kegiatan ini.

3. Semua pihak yang telah terlibat dalam penyelesaian pengabdian ini yang tidak dapat disebutkan satu persatu.

\section{F. DAFTAR PUSTAKA}

Hamida, Naba, Bakti Mulyani dan Budi Utami. (2013). Studi Komparasi Penggunaan Laboratorium Virtual Dan Laboratorium Riil dalam Pembelajaran Student Teams Achievement Division (STAD) Terhadap Prestasi Belajar Ditinjau dari Kreativitas Siswa Pada Materi Pokok Sistem Koloid Kelas XI Semester Genap SMA Negeri 1 Banyudono Tahun Pelajaran 2011/2012. Jurnal Pendidikan Kimia (JPK), Vol. 2 No. 2, 7-15.

Orgill, M., \& Bodner, G. (2004). Contributions of educational research to the practice of chemistry education methods and issues of teaching and learning. Chemistry Education: Research and Practice, 5(1),1532.

Sanova, A. (2017). Pengembangan Lembar Kerja Peserta Didik Praktikum Virtual Kimia SMA Menggunakan Program Chemcollective Berbasis Scientific Approach. Jurnal Sains Sosio Humaniora, 1(2), 220-230.

Slavin, R.E. 2008. Cooperative Learning Theory Research and Practice. Terj.Nurulita Yusron. Bandung: Penerbit Nusa Media.

Tuysuz, Cengis. (2010). The Effect of the Virtual Laboratory on Student Achievment and Attitude in Chemistry. International Online Journal of Educational Sciences, 2 (1), 3753.

Woodfield B.F., Catlin H.R., Waddoups G.L, Moore M.S., Swan R., Allen R. and Bodily G., (2004), The Virtual ChemLab Project: A Realistic and Sophisticated Simulation of Inorganic Qualitative Analysis, Journal of Chemical Education, 18, 1672-1679. 